University of South Carolina

Scholar Commons

1991

\title{
Mathematical Modeling of a Nickel-Cadmium Battery: Effects of Intercalation and Oxygen Reactions
}

Deyuan Fan

Texas A \& M University - College Station

Ralph E. White

University of South Carolina - Columbia, white@cec.sc.edu

Follow this and additional works at: https://scholarcommons.sc.edu/eche_facpub

Part of the Chemical Engineering Commons

\section{Publication Info}

Journal of the Electrochemical Society, 1991, pages 2952-2960.

(c) The Electrochemical Society, Inc. 1991. All rights reserved. Except as provided under U.S. copyright law, this work may not be reproduced, resold, distributed, or modified without the express permission of The Electrochemical Society (ECS). The archival version of this work was published in the Journal of the Electrochemical Society.

http://www.electrochem.org/

DOI: $10.1149 / 1.2085347$

http://dx.doi.org/10.1149/1.2085347

This Article is brought to you by the Chemical Engineering, Department of at Scholar Commons. It has been accepted for inclusion in Faculty Publications by an authorized administrator of Scholar Commons. For more information, please contact digres@mailbox.sc.edu. 


\title{
Mathematical Modeling of a Nickel-Cadmium Battery \\ Effects of Intercalation and Oxygen Reactions
}

\author{
Deyuan Fan* and Ralph E. White* \\ Center for Electrochemical Engineering, Department of Chemical Engineering, Texas A\&M University, \\ College Station, Texas 77843
}

\begin{abstract}
Extensions are presented for a previously published (1) mathematical model of a nickel-cadmium (Ni-Cd) cell. These extensions consist of intercalation thermodynamics for the nickel electrode and oxygen generation and reduction reactions during charge and overcharge. The simulated results indicate that intercalation may be important in the nickel electrode and that including the oxygen reactions provides a means of predicting the efficiency of the cell on charge and discharge.
\end{abstract}

The charge and discharge performance of a sealed $\mathrm{Ni}-\mathrm{Cd}$ cell is of great interest to many researchers as well as manufacturers. Since a sealed Ni-Cd cell is positive limited, many investigations have focused on the nickel electrode. Despite numerous studies, the actual thermodynamics and kinetics of the sintered nickel electrode is still open to debate. Even the reversible potential of the sintered nickel electrode is still far beyond being fully understood. Most researchers (2-7) believe that the reversible potential of a nickel electrode is a function of state of charge, but different formulas have been proposed.

Barnard et al. (2) and Spritzer (3) believe that the cell voltage during discharge is controlled by the reversible potential of the nickel electrode, whereas others (8-10) believe that the cell discharge performance is limited by the solid-state proton diffusion in the nickel electrode. Unfortunately, few quantitative descriptions of the cell discharge voltage have been published and compared to experimental results to determine the validity of either of these assumptions. The predictions presented below show that the intercalation effects may be important. The model presented here may be extended to include solid-state proton diffusion. Consequently, this topic is not discussed further here.

Even less is understood during charge and overcharge of the cell. For example, the oxygen generation and reduction reactions that occur inside the cell are not understood well. Some researchers and engineers (11-13) think that oxygen generated on the nickel electrode during charge is recombined by a chemical process on the active cadmium metal in the negative electrode. This recombination process would require that cadmium metal be oxidized while oxygen is being reduced on the cadmium metal in the negative electrode. It seems unlikely that cadmium would be reduced and oxidized simultaneously at significant rates if the potential of the cadmium metal is negative enough to cause reduction of $\mathrm{Cd}(\mathrm{OH})_{2}$ to $\mathrm{Cd}$. Turner et al. (12-15) questioned this oxygen recombination process and proposed that oxygen is reduced electrochemically on the negative electrode. Consequently, in the model presented here, oxygen is assumed to be reduced electrochemically at the cadmium electrode.

\section{Model Extensions}

A schematic of the nickel-cadmium cell being modeled here is shown in Fig. 1. It consists of a positive electrode, a separator, and a negative electrode. All three components are considered to be porous materials. Two current collectors are located in the middle of the positive and negative electrodes, respectively.

The electrochemical reactions used in the model are as follows

positive electrode

$$
\mathrm{NiOOH}+\mathrm{H}_{2} \mathrm{O}+e^{-} \frac{\text { discharge }}{\overline{\text { charge }}} \mathrm{Ni}(\mathrm{OH})_{2}+\mathrm{OH}^{-}
$$

\footnotetext{
* Electrochemical Society Active Member.
}

$$
\frac{1}{2} \mathrm{O}_{2}+\mathrm{H}_{2} \mathrm{O}+2 e^{-} \underset{\text { charge }}{\rightleftharpoons} 2 \mathrm{OH}^{-}
$$

negative electrode

$$
\begin{gathered}
\mathrm{Cd}+2 \mathrm{OH}^{-} \underset{\text { charge }}{\frac{\text { discharge }}{=} \mathrm{Cd}(\mathrm{OH})_{2}+2 e^{-}} \\
2 \mathrm{OH}^{-} \underset{\text { discharge }}{\overbrace{\text { charge }}} \frac{1}{2} \mathrm{O}_{2}+\mathrm{H}_{2} \mathrm{O}+2 e^{-}
\end{gathered}
$$

The mathematical equations describing the electrochemical reactions, mass transport, and other physical processes within the cell were presented previously (1). The model presented here includes the intercalation thermodynamics for the nickel electrode; and consequently, a new set of thermodynamic and kinetic expressions are included.

The open-circuit potential for an electrochemical reaction $j$, [using Newman's notation (16)]

$$
\sum_{i}^{m} s_{\mathrm{ij}} M_{\mathrm{i}}^{z_{\mathrm{i}}} \rightleftharpoons n_{\mathrm{j}} e^{-}
$$

can be written relative to a given reference electrode reaction $R$ by using the Nernst equation

$$
\begin{aligned}
U_{\mathrm{j}, \mathrm{o}}=U_{\mathrm{j}}^{\theta}-\frac{R T}{n_{\mathrm{j}} F} \sum_{i}^{m} s_{\mathrm{ij}} \ln \left(a_{\mathrm{i}, \mathrm{o}}\right) & \\
-- & {\left[U_{\mathrm{R}}^{\theta}-\frac{R T}{n_{\mathrm{R}} F} \sum_{i}^{m} s_{\mathrm{iR}} \ln \left(a_{\mathrm{i}, \mathrm{R}}\right)\right] }
\end{aligned}
$$

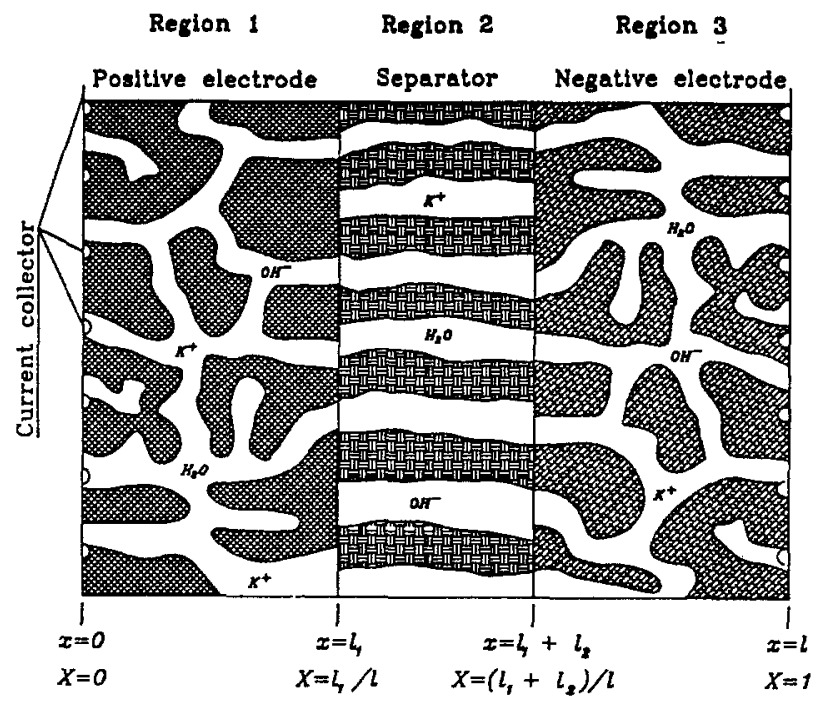

Fig. 1. A schematic of a sintered plate nickel-cadmium (Ni-Cd) battery. 
where i represents each species involved in the reaction, $m$ is the total number of species, and $\alpha_{\mathrm{i}, 0}$ is the relative activity of species $i$, which depends on whether species $i$ is in the solid, liquid, or gaseous state.

The electrode kinetics of reaction $\mathrm{j}$ can be described by the general form of the Butler-Volmer equation

$$
i_{\mathrm{j}}=i_{\mathrm{oj}, \mathrm{o}}\left[\exp \left(\frac{\alpha_{\mathrm{aj}} F}{R T} \eta_{\mathrm{j}}\right)-\exp \left(\frac{-\alpha_{\mathrm{cj}} F}{R T} \eta_{\mathrm{j}}\right)\right]
$$

where the overpotential is given by

$$
\eta_{\mathrm{j}}=\phi_{\mathrm{s}}-\phi_{1}-U_{\mathrm{j}, \mathrm{o}}
$$

and the exchange current density is given by

$$
i_{\mathrm{oj}, \mathrm{o}}=i_{\mathrm{oj}, \mathrm{ref}} \prod_{i}^{m}\left(\frac{a_{\mathrm{i}, \mathrm{j}}}{a_{\mathrm{i}, \mathrm{ref}}}\right)^{\gamma_{\mathrm{ij}}}
$$

in which $i_{\mathrm{oj}, \mathrm{ref}}$ is the exchange current density of reaction $\mathrm{j}$ at a specified reference state. Similarly if we define $U_{\mathrm{j}, \mathrm{ref}}$ to be the equilibrium potential of reaction $j$ at a reference state with respect to a given reference electrode $R$, then

$$
\begin{aligned}
U_{\mathrm{j}, \mathrm{ref}}=U_{\mathrm{j}}^{\ominus}-\frac{R T}{n_{\mathrm{j}} F} \sum_{i}^{m} s_{\mathrm{ij}} \ln \left(\alpha_{\mathrm{i}, \mathrm{ref}}\right) & \\
- & {\left[U_{\mathrm{R}}^{\theta}-\frac{R T}{n_{\mathrm{R}} T} \sum_{i}^{m} s_{\mathrm{i}, \mathrm{R}} \ln \left(a_{\mathrm{i}, \mathrm{R}}\right)\right] }
\end{aligned}
$$

and Eq. [6] becomes

$$
U_{\mathrm{j}, \mathrm{o}}=U_{\mathrm{j}, \mathrm{ref}}-\frac{R T}{n_{\mathrm{j}} F} \sum_{i}^{m} s_{\mathrm{ij}} \ln \left(\frac{a_{\mathrm{i}, \mathrm{o}}}{a_{\mathrm{i}, \mathrm{ref}}}\right)
$$

Substitution of Eq. [9] and [11] into Eq. [7] yields [17]

$$
\begin{aligned}
j_{\mathrm{j}}=a_{\mathrm{j}} i_{\mathrm{oj}, \mathrm{ref}}\left\{\prod_{i}^{n}\left(\frac{a_{\mathrm{i}, \mathrm{o}}}{a_{\mathrm{i}, \mathrm{ref}}}\right)^{\mathrm{p}_{\mathrm{jij}}} \exp \left[\frac{\alpha_{\mathrm{aj}} F}{R T} \eta_{\mathrm{j}, \mathrm{ref}}\right]\right. \\
\left.-\prod_{i}^{n}\left(\frac{a_{\mathrm{i}, \mathrm{o}}}{a_{\mathrm{i}, \mathrm{ref}}}\right)^{\mathrm{a}_{\mathrm{ij}}} \exp \left[\frac{-\alpha_{\mathrm{cj}} F}{R T} \eta_{\mathrm{j}, \mathrm{ref}}\right]\right\}
\end{aligned}
$$

which contains the thermodynamics as well as the kinetics of reaction $j$, where $a_{j}$ is the specific surface area of the porous electrode on which reaction $j$ occurs, $\eta_{\mathrm{j}, \text { ref }}$ is the overpotential with respect to $U_{\mathrm{j}, \mathrm{ref}}$

$$
\eta_{\mathrm{j}, \mathrm{ref}}=\phi_{\mathrm{s}}-\phi_{\mathrm{I}}-U_{\mathrm{j}, \mathrm{ref}}
$$

and

$$
\begin{aligned}
& p_{i j}=\gamma_{i j}+\frac{\alpha_{a j} s_{i j}}{n_{j}} \\
& q_{i j}=\gamma_{i j}-\frac{\alpha_{a j} s_{i j}}{n_{j}}
\end{aligned}
$$

If we assume that the reaction orders of each species in reaction $j$ are consistent with their corresponding stoichiometric coefficients, then

$$
\begin{aligned}
& \text { if } s_{\mathrm{ij}}>0 p_{\mathrm{ij}}=s_{\mathrm{ij}} \text { and } q_{\mathrm{ij}}=0 \\
& \text { if } s_{\mathrm{ij}}<0 p_{\mathrm{ij}}=0 \text { and } q_{\mathrm{ij}}=-s_{\mathrm{ij}}
\end{aligned}
$$

In order to apply Eq. [12] to reactions [1] through [4], some assumptions have to be made. These assumptions are as follows:

1. In the positive electrode, $\mathrm{NiOOH}$ and $\mathrm{Ni}(\mathrm{OH})_{2}$ are assumed to be solid-phase species that coexist in a single solid-solution phase instead of two separate phases. Also it is assumed that their relative activites can be approximated well by their respective mole fractions in the solid state

$$
\begin{aligned}
a_{\mathrm{NiOOH}} & \approx x_{\mathrm{NiOOH}} \\
a_{\mathrm{Ni}(\mathrm{OH})_{2}} & \approx x_{\mathrm{Ni}(\mathrm{OH})_{2}}
\end{aligned}
$$

2. Species other than $\mathrm{NiOOH}$ and $\mathrm{Ni}(\mathrm{OH})_{2}$ in the positive electrode are assumed to be negligible, therefore

$$
x_{\mathrm{NiOOH}}+x_{\mathrm{Ni(OH})_{2}}=1
$$

and the state of charge of the positive electrode $\theta_{p}$ is equal to the mole fraction of the $\mathrm{NiOOH}$ species

$$
\theta_{\mathrm{p}}=x_{\mathrm{NiOOH}}=1-x_{\mathrm{Ni}(\mathrm{OH})_{2}}
$$

3. The reference states for the solid species within the positive electrode are chosen to be at $50 \%$ state of charge

$$
\begin{aligned}
& a_{\mathrm{NiOOH}, \mathrm{ref}}=x_{\mathrm{NiOOH}, \mathrm{ref}}=\frac{1}{2} \theta_{\mathrm{p}} \\
& a_{\mathrm{Ni(OH})_{2, \mathrm{ref}}}=x_{\mathrm{Ni}(\mathrm{OH})_{2}, \mathrm{ref}}=\frac{1}{2} \theta_{\mathrm{p}}
\end{aligned}
$$

4. In the negative electrode, $\mathrm{Cd}$ and $\mathrm{Cd}(\mathrm{OH})_{2}$ exist as two separated solid phases so that their respective solid-state relative activities are unity.

5 . The active electrochemical reaction area of the positive electrode does not change during charge and discharge because the positive electrode is single phase, but the active area of the negative electrode changes as a function of the state of charge due to the nonconductive $\mathrm{Cd}(\mathrm{OH})_{2}$.

6. The relative activity of the hydroxide ion can be approximated by its concentration, which is equal to the concentration of the electrolyte $c$ because $\mathrm{KOH}$ is a 1:1 binary electrolyte.

7. An effective oxygen concentration is introduced to account for the oxygen in both gas and liquid phases; consequently, the two-phase transport of oxygen is simplified by using an effective oxygen diffusion coefficient whose values is between values of gas and liquid diffusion coefficients of oxygen (18).

8. The relative activity of water is assumed to be unity.

It should be noted here that assumption number 2 , which implies that $\theta_{\mathrm{p}}$ varies from 0 to 1 , may be inaccurate particularly with regard to the extreme values of $\theta_{p}=0$ and $\theta_{\mathrm{p}}=1$.

Based on these assumptions, application of Eq. [12] to reactions [1]-[4] results in the following kinetic expressions

$$
\begin{aligned}
& j_{1}=2 \cdot a_{\mathrm{p}} \cdot i_{\mathrm{ol}, \mathrm{ref}}\left\{\left(\frac{c}{c_{\mathrm{ref}}}\right)\left(1-\theta_{\mathrm{p}}\right)\right. \exp \left[\frac{\alpha_{\alpha 1} F}{R T} \eta_{1, \mathrm{ref}}\right] \\
&\left.-\theta_{\mathrm{p}} \exp \left[\frac{-\alpha_{\mathrm{c} 1} F}{R T} \eta_{1, \mathrm{ref}}\right]\right\}
\end{aligned}
$$

$$
\begin{aligned}
j_{2}=a_{\mathrm{p}} \cdot i_{\mathrm{o} 2 \text {,ref }}\left\{\left(\frac{c}{c_{\mathrm{ref}}}\right)^{2}\right. & \exp \left[\frac{\alpha_{22} F}{R T} \eta_{2, \text { ref }}\right] \\
& \left.-\left(\frac{c_{\mathrm{O}_{2}}}{c_{\mathrm{O}_{2, \mathrm{ref}}}}\right)^{1 / 2} \exp \left[\frac{-\alpha_{\mathrm{c} 2} F}{R T} \eta_{2, \text { ref }}\right]\right\}
\end{aligned}
$$

$$
\begin{aligned}
j_{3}=a_{\mathrm{n}} \cdot \theta_{\mathrm{n}}^{\gamma} \cdot i_{\mathrm{o}, \mathrm{ref}}\left\{\left(\frac{c}{c_{\mathrm{ref}}}\right)^{2} \exp \left[\frac{\alpha_{\mathrm{a} 3} F}{R T} \eta_{3, \mathrm{ref}}\right]\right. \\
\\
\left.-\exp \left[\frac{-\alpha_{\mathrm{c} 3} F}{R T} \eta_{3, \mathrm{ref}}\right]\right\}
\end{aligned}
$$

$$
\begin{aligned}
j_{4}=a_{\mathrm{n}} \cdot \theta_{\mathrm{n}}^{\gamma} \cdot i_{\mathrm{o} 4 \text {,ref }}\{ & \left(\frac{c}{c_{\mathrm{ref}}}\right)^{2} \exp \left[\frac{\alpha_{\mathrm{a} 4} F}{R T} \eta_{4, \mathrm{ref}}\right] \\
& \left.-\left(\frac{c_{\mathrm{O}_{2}}}{c_{\mathrm{O}_{2, \mathrm{ref}}}}\right)^{1 / 2} \exp \left[\frac{-\alpha_{\mathrm{c} 4} F}{R T} \eta_{4, \text { ref }}\right]\right\}
\end{aligned}
$$

where $a_{\mathrm{p}}$ and $a_{\mathrm{n}}$ are the electrochemically active surface areas of the positive and negative electrodes, respectively, at $100 \%$ state of charge. Note that the electrochemically active area of the positive electrode is fixed whereas the electroactive area of the negative electrode, $a_{n} \theta_{n}^{y}$, changes with the state of charge of the negative electrode. The state of 
Table I. Fixed physical parameters.

\begin{tabular}{cl}
\hline Parameter & \multicolumn{1}{c}{ Value } \\
\hline$T$ & $298.15 \mathrm{~K}$ \\
$\rho_{o}$ & $1.0 \times 10^{-3} \mathrm{~kg} / \mathrm{cm}^{3}$ \\
$F$ & $96,487 \mathrm{C} / \mathrm{equiv}$ \\
$t^{0_{-}}$ & $0.22[(23), \mathrm{p} .598]$ \\
$\kappa$ & $0.67 \mathrm{~S} / \mathrm{cm}[(23) \mathrm{p} .593]$
\end{tabular}

charge of the negative electrode is defined as the amount of cadmium metal over the total amount of cadmium metal over the total amount of active material in the negative electrode, and its value can be approximated in terms of porosity

$$
\theta_{\mathrm{n}}=\frac{\varepsilon-\varepsilon_{\mathrm{o}}}{\varepsilon_{\max }-\varepsilon_{\mathrm{o}}}
$$

where $\varepsilon_{\max }$ and $\varepsilon_{\mathrm{o}}$ are the porosities of the negative electrode at fully charged and fully discharged states, respectively, and

$$
\begin{gathered}
\varepsilon_{\mathrm{max}}=\varepsilon_{\mathrm{sub}}\left(1-\frac{L}{\rho_{\mathrm{Cd}(\mathrm{OH})_{2}}}\right) \\
\varepsilon_{\mathrm{o}}=\varepsilon_{\mathrm{sub}}\left(1-\frac{L M_{\mathrm{Cd}}}{\rho_{\mathrm{Cd}} M_{\mathrm{Cd}(\mathrm{OH})_{2}}}\right)
\end{gathered}
$$

where $\varepsilon_{\text {sub }}$ is the porosity of the substrate plaque, $L$ is the loading level of the active material in the porous electrode $\left[\mathrm{g} / \mathrm{cm}^{3}\right.$ void volume), $\rho_{\mathrm{Cd}}, \rho_{\mathrm{Cd}(\mathrm{OH})_{2}}$ are the densities of the cadmium and cadmium hydroxide, respectively, and $M_{\mathrm{Cd}}$, $M_{\mathrm{Cd}(\mathrm{OH})_{2}}$ are the molecular weights of the cadmium and cadmium hydroxide, respectively.

The open-circuit potential for reaction [1] given above includes the state of charge of the positive electrode but does not provide values for the open-circuit potential which agree with experimental data. Barnard et al. (2) and Spritzer (3) have derived an equilibrium potential expression for the nickel electrode based on thermodynamic theory (Margules and Van Laar equations)

$$
\begin{aligned}
& U_{1, \mathrm{eq}}=U_{1}^{\theta}-\frac{R T}{F} \ln \left[\mathrm{OH}^{-}\right] \\
&+\frac{R T}{F} \ln \frac{\theta_{\mathrm{p}}}{1-\theta_{\mathrm{p}}}+\frac{R T}{F} k(2 \theta-1)
\end{aligned}
$$

This equation can be written in the form needed here; that is, according to Eq. [10], the open-circuit potential of reaction [1] relative to a reference electrode, $R$, can be written as

$$
\begin{aligned}
U_{1, \mathrm{ref}}=U_{1}^{\theta}-\frac{R T}{F} \ln \left[\mathrm{OH}^{-}\right] & +\frac{R T}{F} \ln \frac{\theta_{\mathrm{p}}}{1-\theta_{\mathrm{p}}}+\frac{R T}{F} k\left(2 \theta_{\mathrm{p}}-1\right) \\
- & {\left[U_{\mathrm{R}}^{\theta}-\frac{R T}{n_{\mathrm{R}} F} \sum_{i}^{m} s_{\mathrm{i}, \mathrm{R}} \ln \left(a_{\mathrm{i}, \mathrm{R}}\right)\right] }
\end{aligned}
$$

where the constant $k$ can be used to account for the deviation of the solid solution from its ideal state. The magnitude of its value is a measure of the interaction between
Table III. Reaction orders and transport properties of components in liquid phase.

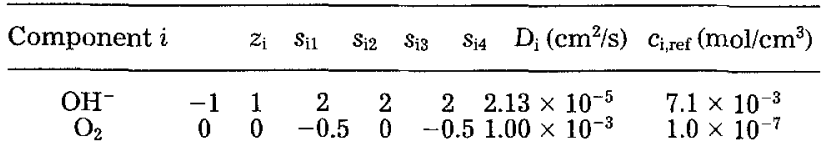

Table IV. Kinetic and thermodynamic parameters for the reactions in a Ni-Cd battery.

\begin{tabular}{ccccccc}
\hline Reaction $j$ & $\alpha_{\mathrm{aj}}$ & $\alpha_{\mathrm{cj}}$ & $n_{\mathrm{j}}$ & $i_{\mathrm{oj}, \mathrm{ref}\left(\mathrm{A} / \mathrm{cm}^{2}\right)}$ & $U_{\mathrm{i}}^{\mathrm{\theta}}(\mathrm{V})$ & $U_{\mathrm{i}, \mathrm{ref}}(\mathrm{V}, \mathrm{SHE})$ \\
\hline$[1]$ & 0.5 & 0.5 & 1 & $6.1 \times 10^{-5}(25)$ & $+0.490(26)$ & +0.440 \\
{$[2]$} & 1.5 & 0.5 & 2 & $1.0 \times 10^{-11}$ & $+0.401(26)$ & +0.351 \\
{$[3]$} & 1.0 & 1.0 & 2 & $6.1 \times 10^{-5}(25)$ & $+0.809(26)$ & -0.859 \\
{$[4]$} & 1.5 & 0.5 & 2 & $1.0 \times 10^{-14}$ & $+0.401(26)$ & +0.351
\end{tabular}

species in the solid solution. According to Barnard et al. (2) and Spritzer (3), positive and negative values of $k$ depict, respectively, positive and negative deviations from ideality. A $k$ value of two is a special case representing the borderline between a single-phase and a two-phase system. When $k$ is greater than two, phase separation will take place $(2,3)$. The formula in Eq. [27] has been experimentally confirmed $(3,19)$. Spritzer (3) obtained an intercalation constant of 0.789 for the nickel electrode by fitting experimental data. Unfortunately, not enough data from well-defined cells exist for comparison to our model predictions, and the data by Spritzer do not include the kinetic effects. Consequently, we have used $k=0$ for most of the predictions presented here.

The above set of thermodynamic and kinetic expressions were incorporated into the model equations presented previously (1). The governing equations and boundary conditions were also adjusted to include these equations. The resulting set of partial differential equations was discretized into finite difference form and solved numerically using a modified BAND(J) solver (20). The parameters needed for the calculations are listed in Table IV.

\section{Results and Discussion}

Intercalation effect.-Discharge.-Simulated cell discharge curves are shown on Fig. 2 for a constant discharge rate of $10 \mathrm{~mA} / \mathrm{cm}^{2}$ (approximately equal to a $\mathrm{C} / 2$ rate where $C=$ charge capacity $\times$ thickness of nickel electrode $=2082$ $\mathrm{C} / \mathrm{cm}^{3} \times 0.036 \mathrm{~cm} / 3600 \mathrm{~s}=0.02082 \mathrm{Ah} / \mathrm{cm}^{2}$ or $20.82 \mathrm{mAh} /$ $\mathrm{cm}^{2}$ ) with different values of the intercalation constant. The overall slope of the discharge curve becomes less steep as the intercalation constant changes from -1 to +1 . When the intercalation constant is 2 , the middle section of cell voltage is tangential to a horizontal line. This result is consistent with Barnard et als derivations (2). The potentials of the positive and the negative electrodes are shown in Fig. 3. The potential of the positive electrode potential shows the same shape as that of the cell voltage, while the potential of the negative electrode remains primarily constant during the discharge process. This is consistent with

\begin{tabular}{|c|c|c|c|c|}
\hline Property & $\begin{array}{c}\text { Positive } \\
\text { (region 1) }\end{array}$ & $\begin{array}{l}\text { Separator } \\
\text { (region 2) }\end{array}$ & $\begin{array}{l}\text { Negative } \\
\text { (region 3) }\end{array}$ & Ref. \\
\hline Half thickness, cm & 0.036 & 0.0125 & 0.040 & $(24)$ \\
\hline $\begin{array}{l}\text { Loading level, } L, \mathrm{~g} / \mathrm{cm}^{\circ} \text { vold vol. } \\
\text { Max. charge, }\left(Q_{\mathrm{m}}, \mathrm{C} / \mathrm{cm}^{3}\right.\end{array}$ & $\begin{array}{r}1.60 \\
2082\end{array}$ & - & $\begin{array}{r}1.90 \\
3032\end{array}$ & $(24)$ \\
\hline Surface area, $a, \mathrm{~cm}^{2} / \mathrm{cm}^{3}$ & $5 \times 10^{4}$ & - & $5 \times 10^{4}$ & $(24)$ \\
\hline Tortuosity exponents, ex/exm & $2.5 / 0.5$ & 2.5 & $2.5 / 0.5$ & \\
\hline
\end{tabular}
the fact that the Ni-Cd cell is a positive electrode limited cell.

Charge.-Figure 4 presents the simulated cell charge curves for a constant charge rate of $10 \mathrm{~mA} / \mathrm{cm}^{2}$ with different values of the intercalation constant. The results are

Table II. Properties of the electrodes and the separator. 


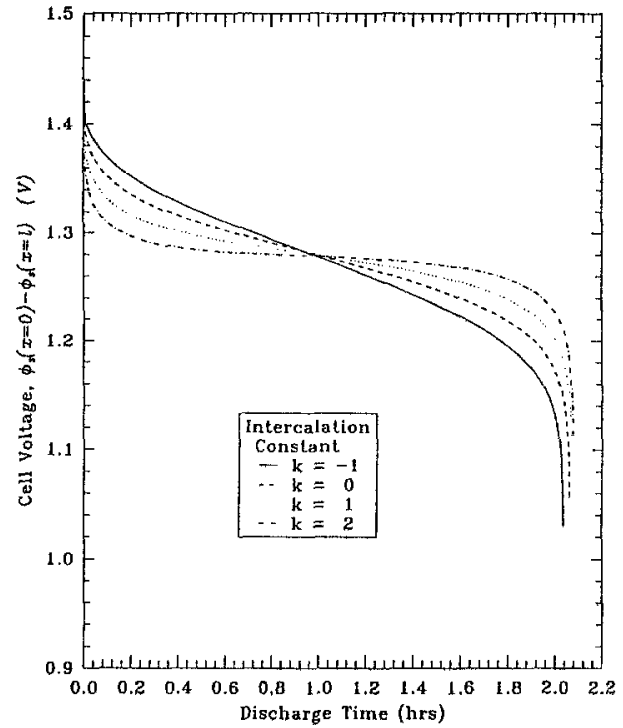

Fig. 2. The effect of intercalation on the discharge performance of a nickel-cadmium battery $\left(i_{\text {cell }}=10 \mathrm{~mA} / \mathrm{cm}^{2}\right)$.

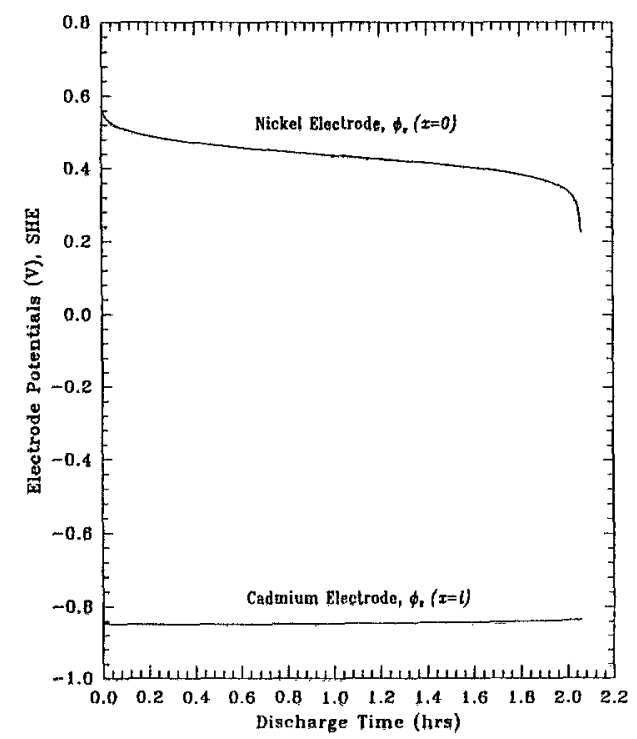

Fig. 3. Nickel and cadmium electrode potentials during discharge at constant rate $\left(i_{\text {cell }}=10 \mathrm{~mA} / \mathrm{cm}^{2}\right.$ and $\left.k=0\right)$.

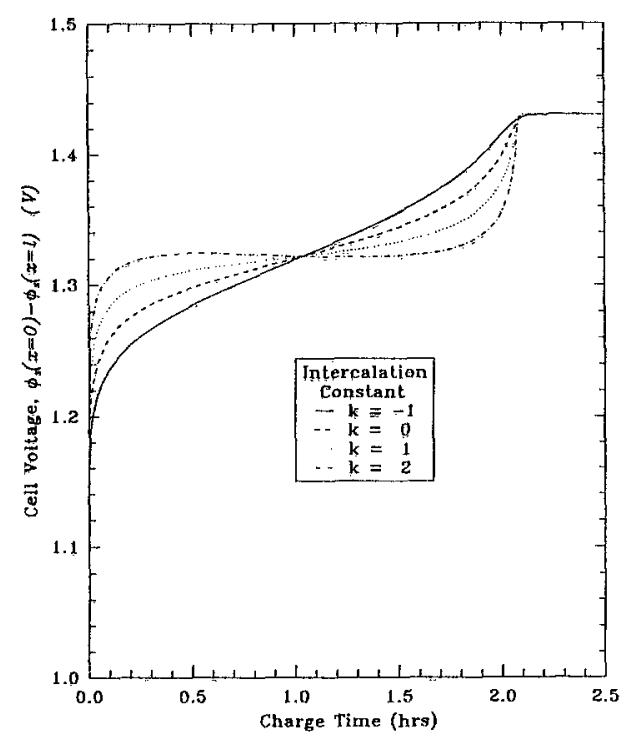

Fig. 4. Effect of intercalation on the charge performance of a nickelcadmium battery $\left(i_{\text {cell }}=10 \mathrm{~mA} / \mathrm{cm}^{2}\right)$.

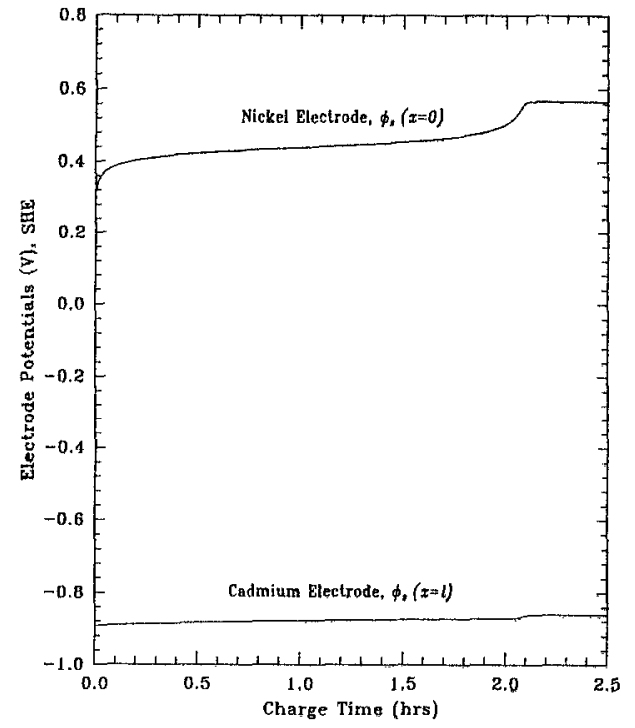

Fig. 5. Nickel and cadmium electrode potentials during charge at constant rate $\left(i_{\text {cell }}=10 \mathrm{~mA} / \mathrm{cm}^{2}\right.$ and $\left.k=0\right)$.

similar to those obtained during discharge. The overall slope of cell charge voltage becomes less steep as the intercalation constant changes from -1 to 1 . When $k=2$, the charge voltage curve is again tangential to a horizontal line at the middle of the curve. During overcharge the reactions in the cell are dominated by the oxygen reactions, therefore, the cell voltage is independent of both the intercalation constant and time, as shown in Fig. 4 for $t>2 \mathrm{~h}$.

The individual electrode potentials during charge are shown in Fig. 5. Again the potential of the positive electrode has the same shape as that of the cell voltage. The potential of the negative electrode increases slightly during charge and has a small positive shift at the beginning of overcharge. The small shift is due to the switch of the electrochemical reaction from cadmium reduction to oxygen reduction, as explained further below. During overcharge, both the positive and the negative electrode potentials have constant values.

Oxygen reactions.-Oxygen reactions during constant rate charge.-It is well-known that the oxygen reaction is an important consideration for a nickel-cadmium battery during charge and overcharge. It not only affects the charge efficiency, it also causes pressure build-up in the cell during overcharge. Figure 6 presents the charge efficiency ${ }^{1}$ as well as the state of charge ${ }^{2}$ with respect to time during a constant rate charge. The charge efficiency stays high at nearly $100 \%$ at low states of charge, but drops quickly when the state of charge is over $90 \%$. During overcharge, the charge efficiency is simply zero (i.e., all the current is consumed by the oxygen reactions and no current is used on charging the active materials). Figure 7 shows the current densities due to reaction [1]-[4]. Note that at the early states of the charge the main reaction [1] and [3] have current density values of 10 and $-10 \mathrm{~mA} / \mathrm{cm}^{2}$, respectively, and the current densities due to the oxygen reactions [2] and [4] are essentially zero. When the state of charge increases $90 \%$, the oxygen reaction begins and the current used to charge the active materials begins to decrease. During this period, the oxygen generation rate increases quickly. The oxygen generated in the positive electrode is assumed to diffuse through the separator in both the liquid and gas pores, as represented by an effective oxygen concentration (1), and will be consumed at the negative electrode according to reaction [4]. As shown in Fig. 7, the current density for oxygen reduction during overcharge is equal to the current density for oxygen generation. Also, note there is no current density for cadmium oxidation to cadmium hydroxide in the negative electrode. This indi-

${ }^{1}$ Charge efficiency is defined to be the ratio of the current density due to reaction [1] to the total cell charge current density.

${ }^{2}$ Since the nickel-cadmium cell is positive electrode limited, the state of charge of the cell is that of the positive electrode. 


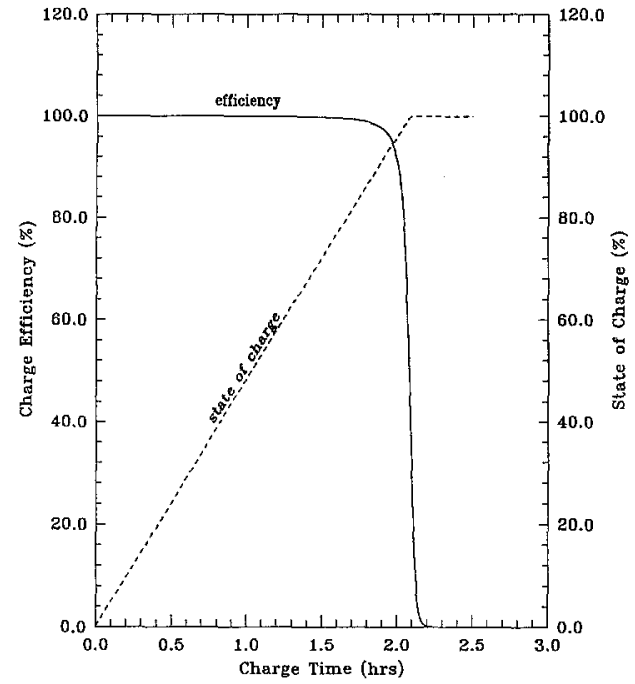

Fig. 6. Efficiency and state of charge during a constant rate charge $\left(i_{\text {cell }}=10 \mathrm{~mA} / \mathrm{cm}^{2}\right.$ and $k=0$ ).

cates that the oxygen generated in the positive electrode is reduced by reaction [4] and that cadmium is not oxidized to cadmium hydroxide during overcharge according to the model presented here.

Figures 8 and 9 present the local transfer current distributions $\left(j_{1}-j_{4}\right)$ during charge and overcharge for the main reactions [1], [3] and the oxygen reactions [2], [4], respectively. According to Fig. 8, the transfer current distributions for the main reactions are somewhat nonuniform along the $X$ coordinate at the beginning of charge. The positive values of the local transfer current in the nickel electrode indicate that the active material of nickel hydroxide is being oxidized to nickel oxyhydroxide during charge. The negative values of the local transfer current in the cadmium electrode indicate that cadmium hydroxide is being reduced to cadmium during charge. When the recharge ratio ${ }^{3}$ is over 0.9 , the transfer currents for the main reactions begin to drop. The transfer currents of the main reactions in both electrodes go to zero at a recharge ratio of about 1.1 and remain zero during the rest of the overcharge period. Figure 9 shows that the oxygen transfer currents are zero everywhere before reaching a recharge ratio of 0.9. After that, the transfer currents for the oxygen reactions in both electrodes increase quickly. In the nickel electrode, the

${ }^{3}$ The recharge ratio is defined as the actual amount of charge put into the cell relative to the theoretical capacity of the cell.

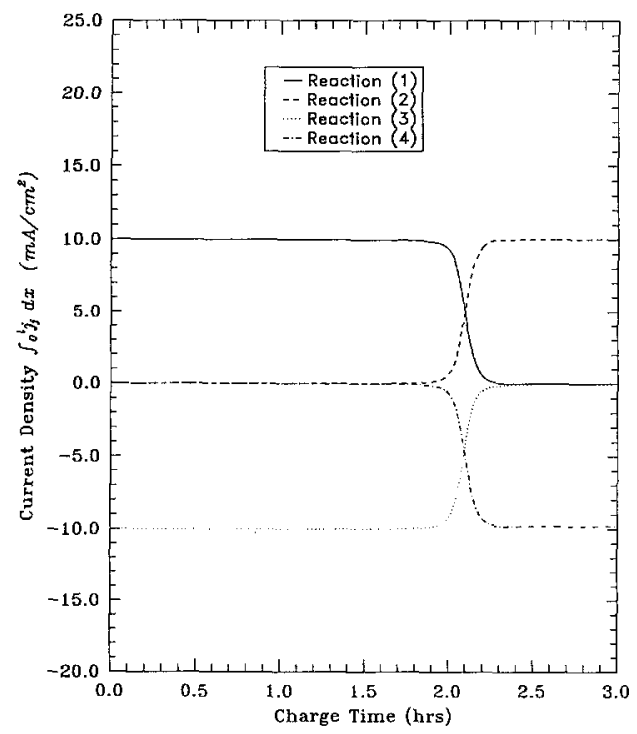

Fig. 7. The current density due to reactions [1]-[4] during charge and overcharge at constant rate $\left(i_{\text {cell }}=10 \mathrm{~mA}\right.$ and $\left.k=0\right)$.

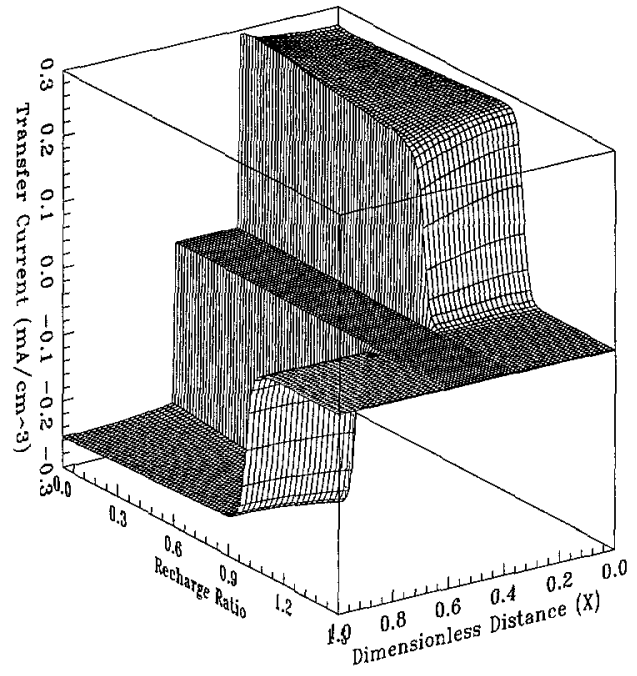

Fig. 8. Three-dimensional view of the transfer current distributions due to main reactions [1] and [3] during constant rate charge and overcharge $\left(i_{\text {cell }}=10 \mathrm{~mA}\right.$ and $\left.k=0\right)$.

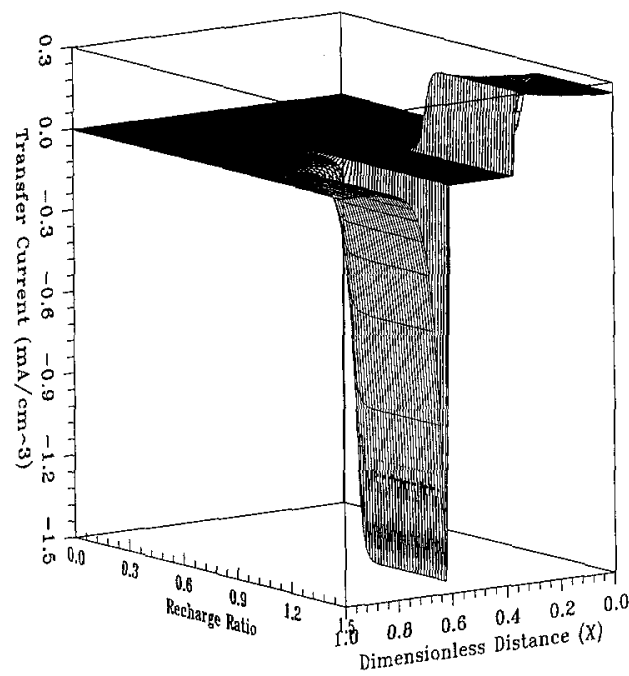

Fig. 9. Three-dimensional view of the transfer current distributions due to the oxygen reactions [2] and [4] during constant rate charge and overcharge $\left(i_{\mathrm{cell}}=10 \mathrm{~mA} / \mathrm{cm}^{2}\right.$ and $\left.k=0\right)$.

transfer current for oxygen generation increases almost uniformly along the X-coordinate, which means that oxygen generation occurs everywhere within the positive electrode. In the cadmium electrode, the transfer current for the oxygen reduction reaction is very large near the separator but remains essentially zero at the back of the electrode. As a result of this, a very steep gradient of the oxygen reduction transfer current is developed in the cadmium electrode, which indicates that the electrochemical oxygen reduction reaction mainly occurs within a small region of the cadmium electrode near the separator.

Figure 10 presents the effective oxygen concentration profiles. Once oxygen generation begins, the effective oxygen concentration in the positive electrode increases rapidly within a short period of time. This indicates that charging at a constant rate will result in a dramatic pressure buildup within the cell in a very short period of time. During overcharge (recharge ratio $>1.0$ ), oxygen generation and reduction reaches a steady state, therefore the oxygen concentration profile remains unchanged. This steady state during overcharge can be observed from other variables, such as cell voltage, electrode potentials, and reactions currents (see Fig. 4-9).

Oxygen reactions during constant rate charge to a limiting voltage.-A very important charging technique developed to avoid high pressure buildup during overcharge is the 


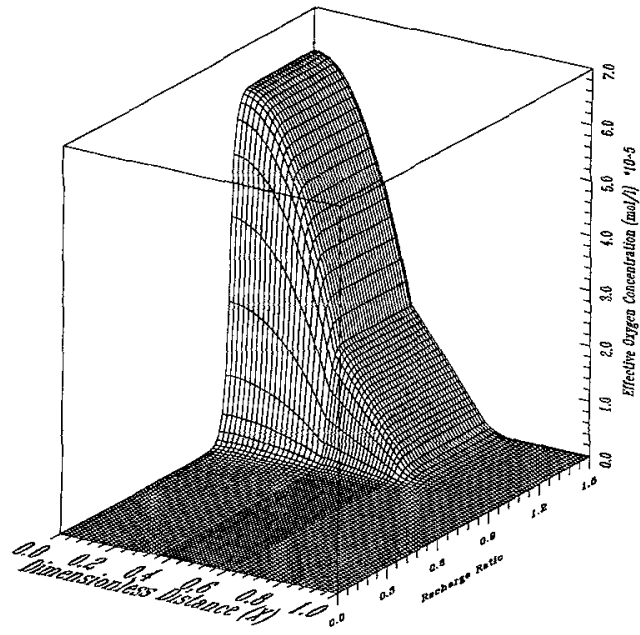

Fig. 10. Three-dimensional view of the effective oxygen concentration changes during charge and overcharge at constant rate $\left(i_{\text {cell }}=10 \mathrm{~mA} / \mathrm{cm}^{2}\right.$ and $k=0$ ).

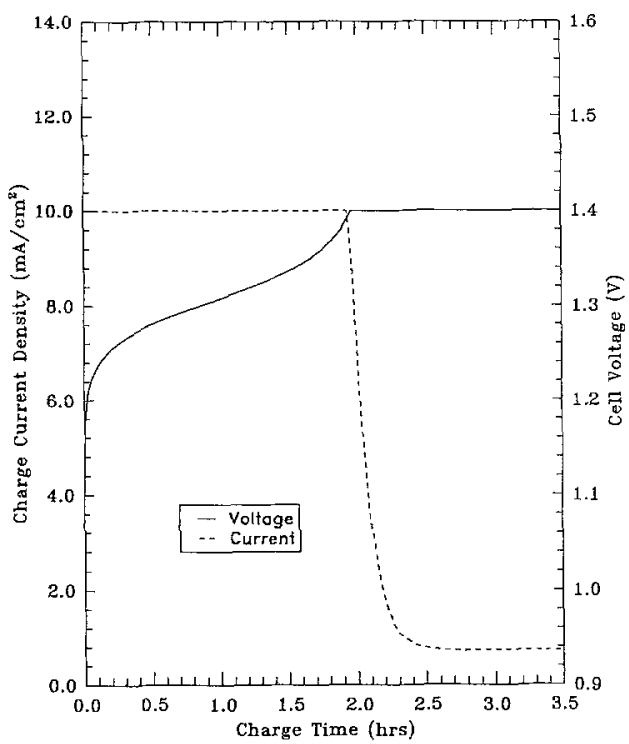

Fig. 11. Charge current density and cell voltage during charge at a constant rate of $10 \mathrm{~mA} / \mathrm{cm}^{2}$ to $1.40 \mathrm{~V}$ and then switched to constant voltage charge $(k=0)$.

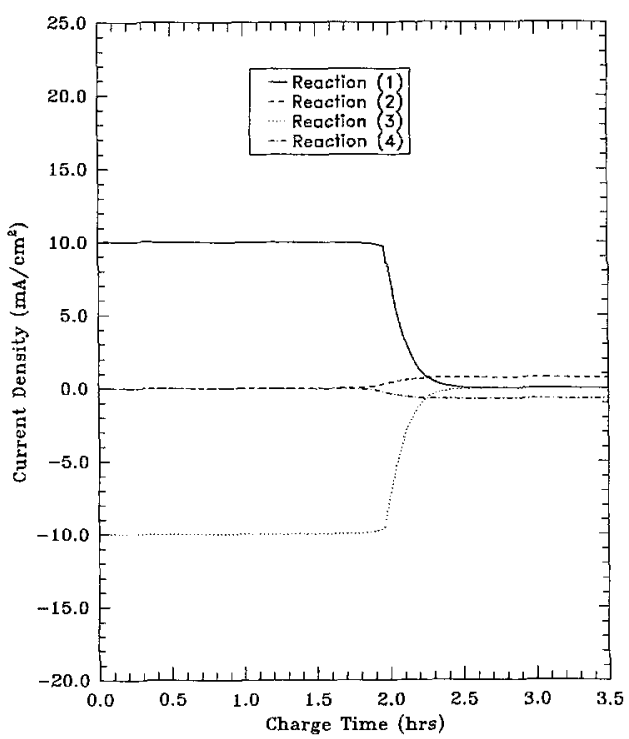

Fig. 12. The current densities associated with reactions [1]-[4] during charge at a constant rate $10 \mathrm{~mA} / \mathrm{cm}^{2}$ to $1.40 \mathrm{~V}$ and then switched to constant voltage charge $(k=0)$.

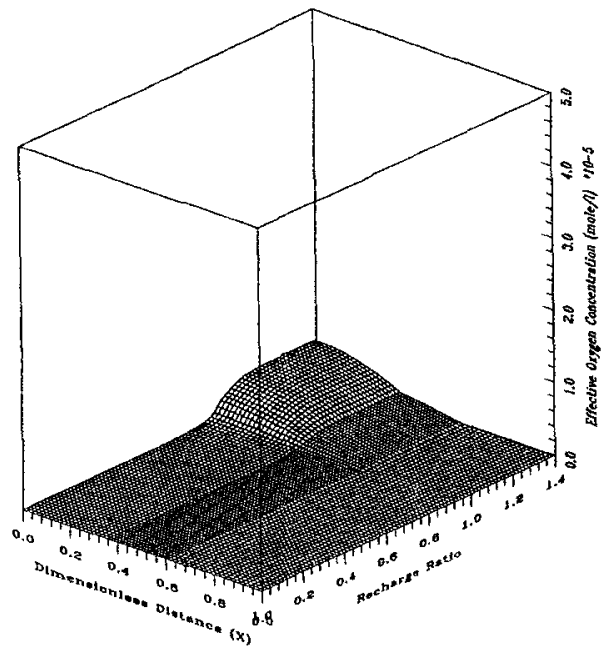

Fig. 13. Three-dimensional view of the effective oxygen concentration during charge at a constant rate of $10 \mathrm{~mA} / \mathrm{cm}^{2}$ charge to $1.40 \mathrm{~V}$ and then switch to constant voltage charge $(k=0)$.

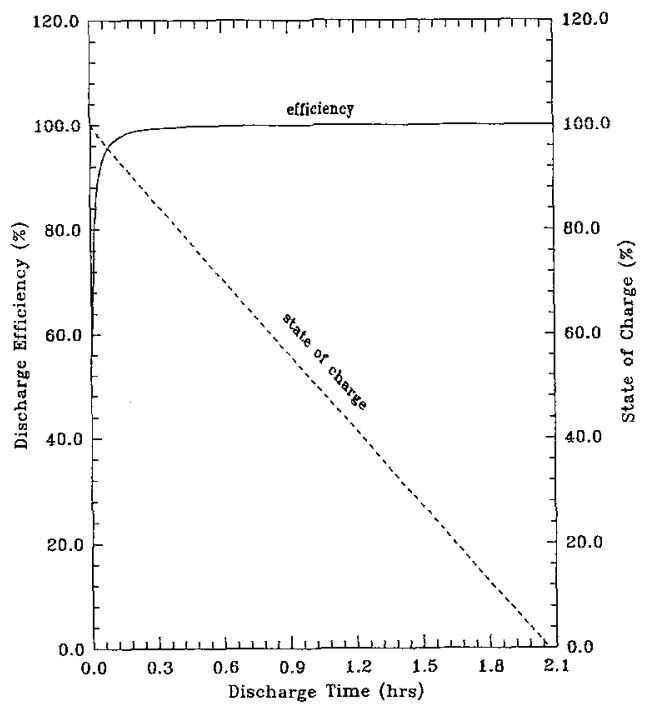

Fig. 14. Discharge efficiency and state of charge during discharge at a constant rate of $10 \mathrm{~mA} / \mathrm{cm}^{2}(k=0)$.

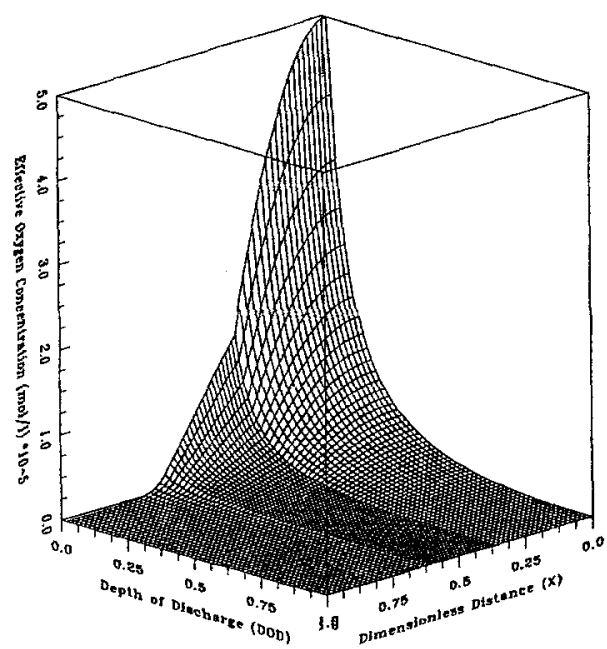

Fig. 15. Three-dimensional view of the effective oxygen concentration during discharge ot a rate of $10 \mathrm{~mA} / \mathrm{cm}^{2}(k=0)$.

so-called "constant rate charge to a limiting voltage." Figure 11 contains a cell voltage curve and charge current density curve for a constant voltage charge mode. The 


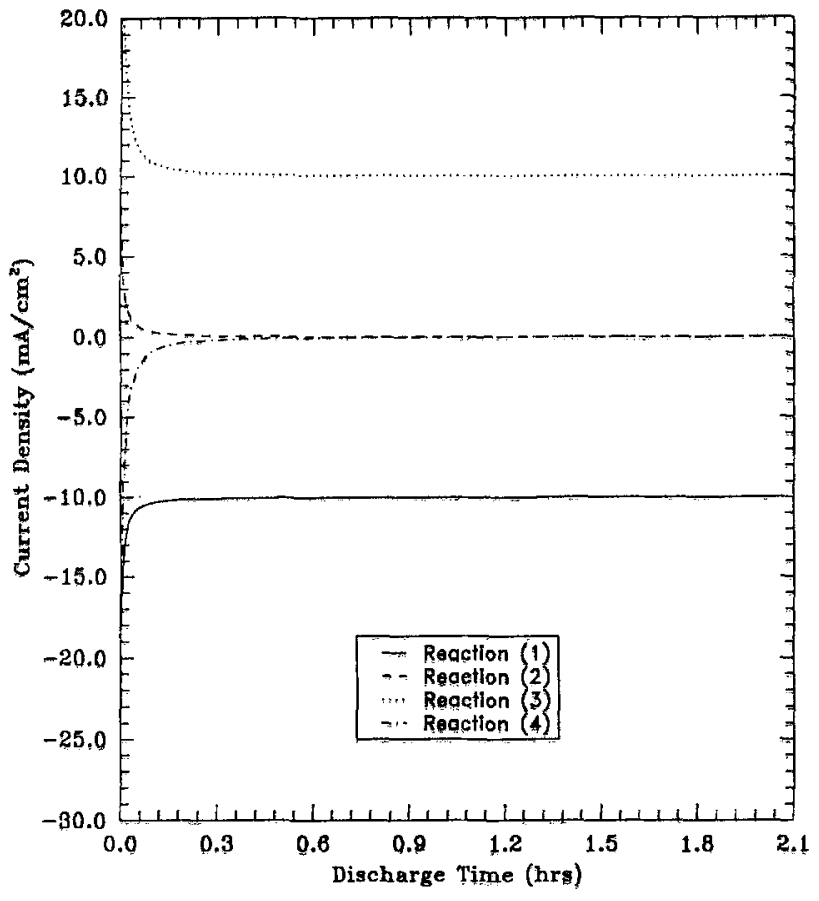

(a)

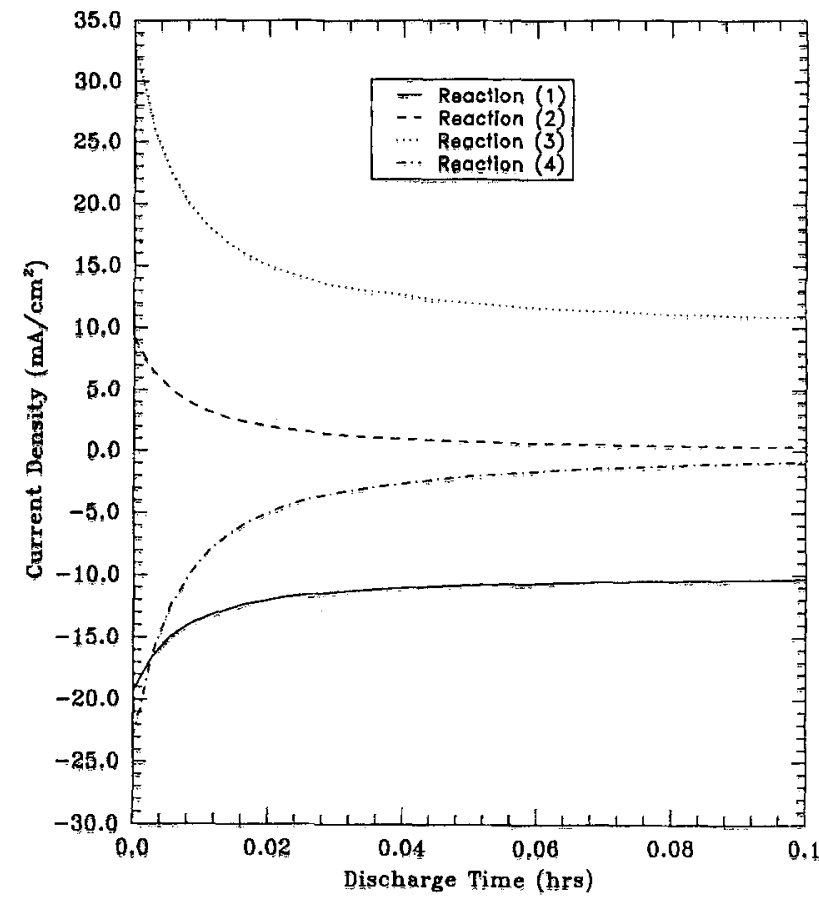

(b)

Fig. 16. The current densities due to reqctions [1] [4] during discharge at constant rate of $10 \mathrm{~mA} / \mathrm{cm}^{2}$ (o) oyer entire discharge period, (b) within the first 6 min.

charge begins with a constant rate of $10 \mathrm{~mA} / \mathrm{cm}^{2}$ and proceeds until the cell voltage reaches a set value $(1.40 \mathrm{~V}$ in this case); the cell voltage is then controlled at this value and the charge current density is allowed to fall off. The charge current density drops quickly to a very small value (about $0.6 \mathrm{~mA} / \mathrm{cm}^{2}$ ); at the same time, the current densities associated with the main reactions [1], [3] decrease and approach zero at charge time of $2.5 \mathrm{~h}$. The steady-state overcharge current density is again due to the oxygen reactions only, as shown in Fig. 12, but the rate of these reactions is much smaller.

A three-dimensional view of the effective oxygen concentration profiles is shown on Fig. 13. Compared to Fig. 10 , the effective oxygen concentration in the positive electrode region during overcharge is reduced significantly by using the voltage control charge mode. It is necessary to point out that choosing a proper value for the set voltage is very important. If the voltage is set too high, the purpose of avoiding the oxygen pressure buildup cannot be satisfied. If on the other hand, the voltage is set too low, the cell cannot be charged to the maximum state of charge:

Oxygen reaction during discharge.-One interesting phenomena observed from the cell modeling results is that the discharge efficiency is less than $100 \%$ at the early stages of discharge. Figure 14 presents the discharge efficiency ${ }^{4}$ during discharge at a constant current density of $10 \mathrm{~mA} / \mathrm{cm}^{2}$. The discharge efficiency is only $50 \%$ at the beginning of discharge and quickly increases to $100 \%$ as the discharge process proceeds. Our explanation for this is that before the beginning of discharge, the potential of the positive electrode is higher than the equilibrium potential of the oxygen reaction; therefore, oxygen is produced by oxidizing $\mathrm{OH}^{-}$ions in the positive electrode region. As a result of this, more positive active material is consumed (discharge direction of reaction [1]). This is equivalent to a self-discharge process which was studied by Conway and Liu (21) and recently by Mao and White (22) for the $\mathrm{Ni} / \mathrm{H}_{2}$ cell. Figure 15 shows that in early stages of discharge oxygen is generated in the positive electrode and is reduced in the negative electrode.

Figures 16a and $b$ are the current densities associated with reaction [1]-[4] during discharge (discharge begins im-

\footnotetext{
${ }^{4}$ Discharge efficiency is defined as the ratio of the cell discharge current density to the current density due to reaction [1].
}

mediately after steady-state overcharge). At the beginning of discharge, since the potential of the nickel electrode is still high, oxygen is generated in the positive electrode according to reaction [2], therefore its current density has a positive value. At the same time, nickel oxy-hydroxide is being reduced according to reaction [1], and its current density value has a negative value, but its absolute value is greater than the discharge current density of the cell $\left(10 \mathrm{~mA} / \mathrm{cm}^{2}\right)$, which means that reaction [1] is occurring at a rate which is higher than the rate of discharge. This extra amount of current is spent on producing oxygen. A similar process occurs in the negative electrode, however, since oxygen was accumulated during the overcharge period, the oxygen reduction current at the beginning of discharge is higher than that of the oxygen generation current. After the accumulated oxygen is consumed, the reduction rate drops rapidly. According to the model, the accumulated oxygen is consumed very quickly (within about $2 \mathrm{~min}$ ). As the discharge process proceeds, the potential of the positive electrode falls below the oxygen equilibrium potential; consequently, the production of oxygen in the positive electrode stops, the reduction of oxygen in the negative electrode ceases, and the discharge efficiency approaches $100 \%$.

\section{Conclusion}

A mathematical model presented here can be used to predict the cell discharge, charge, and overcharge performance. The model simulations indicate that interaction between solid-state species in the nickel electrode (intercalation) may affect the cell charge and discharge voltage curves. According to the model, oxygen is generated in the positive electrode and is electrochemically reduced in the negative electrode and these reactions affect the efficiency of the charge and discharge processes.

\section{Acknowledgments}

The authors acknowledge gratefully that this work was supported by the Jet Propulsion Laboratory (NASA) under contract No. 958344. We would like to thank Gerald Halpert, Karla Clark, Paul Timmerman, Sal DiStefano, and Peter Gluck for their helpful discussion and for providing many of the parameter values used in the model. We would also like to thank Dr. D. Turner for his valuable suggestions and comments on this work. 
Manuscript submitted Oct. 15, 1990; revised manuscript received Feb. 10, 1991.

Texas A\&M University assisted in meeting the publication costs of this article.

\section{LIST OF SYMBOLS}

$a_{i, 0} \quad$ relative activity of species $i$ at reaction site $\left(a_{i, o}=c_{i, o} / \rho_{o}\right.$ for solutes with $c_{i, o}$ in mol/liters mol $/ \mathrm{kg}$ of solvent; $a_{i, o}=x_{i, o}$ for solid species, $a_{i, o}=p_{i, o}$ for gas species, atm, and $a_{0,0}=\lambda_{0,0} / \lambda_{0}^{\circ}$ )

$a_{i, \text { ref }} \quad$ relative activity of species $i$ at reference state

$a_{j} \quad$ specific surface area for reaction $j, \mathrm{~cm}^{2} / \mathrm{cm}^{3}$

$a_{n} \quad$ electrochemically active surface area of the negative electrode at fully charged state, $\mathrm{cm}^{2} / \mathrm{cm}^{3}$

$a_{p} \quad$ electrochemically active surface area of the positive electrode, $\mathrm{cm}^{2} / \mathrm{cm}^{3}$

c concentration of the electrolyte $(\mathrm{KOH}), \mathrm{mol} / \mathrm{cm}^{3}$

$c_{\text {ref }}$ reference concentration of the electrolyte, $\mathrm{mol} / \mathrm{cm}^{3}$

$\mathrm{C}_{\mathrm{O}_{2}}$ effective concentration of oxygen in the liquid phase, $\mathrm{mol} / \mathrm{cm}^{3}$

$c_{\mathrm{O}_{2, \text { ref }}}$ reference effective concentration of oxygen in the liquid phase, $\mathrm{mol} / \mathrm{cm}^{3}$

$D_{\mathrm{i}} \quad$ diffusion coefficient of species $i, \mathrm{~cm}^{2} / \mathrm{s}$

$D_{\mathrm{O}_{2}}$ effective diffusion coefficient of oxygen, $\mathrm{cm}^{2} / \mathrm{s}$

ex $j$ exponent to account for the tortuosity effect of the porous media in regions $j$ for liquid properties (diffusion coefficients and conductivities) $(j=1,2,3)$

$\operatorname{exm} j$ exponent to account for the tortuosity effect of the porous media in regions $j$ for solid properties (conductivity) $(j=1,3)$

F Faraday's constant, 96,487 C/equiv

$i_{\mathrm{j}} \quad$ current density associated with reaction $j, \mathrm{~A} / \mathrm{cm}^{2}$

$i_{\mathrm{oj}, \mathrm{o}} \quad$ exchange current density of reaction $j$ at reaction site, $\mathrm{A} / \mathrm{cm}^{2}$

$i_{\mathrm{oj}, \mathrm{ref}} \quad$ exchange current density of reaction $j$ at reference state, $\mathrm{A} / \mathrm{cm}^{2}$

$i_{j} \quad$ transfer current of reaction $j, \mathrm{~A} / \mathrm{cm}^{3}$

$k$ interaction constant for an intercalation electrode

$L \quad$ loading level of the active materials in a porous electrode, $\mathrm{g} / \mathrm{cm}^{3}$ void volume

total thickness of a cell unit, $\mathrm{cm}$

$l_{1} \quad$ half thickness of the nickel electrode, $\mathrm{cm}$

$l_{2} \quad$ thickness of the separator, $\mathrm{cm}$

$M_{\mathrm{i}} \quad$ molecular weight of species $i, \mathrm{~g} / \mathrm{mol}$

$n_{\mathrm{j}} \quad$ number of electrons involved in the electrode reaction $j$

$p_{\mathrm{ij}} \quad$ reaction order of anodic reactant $i$ in reactions $j$

$q_{i j} \quad$ reaction order of cathodic reactant $i$ in reactions $j$

$R$ universal gas constant, $8.3143 \mathrm{~J} / \mathrm{mol}-\mathrm{K}$

$s_{\mathrm{ij}} \quad$ stoichiometric coefficient of species $i$ in reactions $j$

$t^{\mathrm{s}}$ transference number of $\mathrm{OH}^{-}$species in $\mathrm{KOH}$ solution

$T \quad$ absolute temperature, $\mathrm{K}$

$U_{j, 0} \quad$ equilibrium potential of reaction $j$ at reaction site, V (SHE)

$U_{\mathrm{j}, \text { ref }}$ equilibrium potential of reaction $j$ at reference state, V(SHE)

$U_{j}^{\natural} \quad$ standard thermodynamic potential of reaction $j$, $\mathrm{V}$ (SHE)

$x \quad$ dimensional spatial coordinate, $\mathrm{cm}$

$x_{\mathrm{i}} \quad$ mole fraction of species $i$ in the solid state, where $i=\mathrm{NiOOH}, \mathrm{Ni}(\mathrm{OH})_{2}$

$X$ dimensionless spatial distance from the center of the positive electrode (see Fig. 1)

$z_{\mathrm{i}} \quad$ charge of species $i$

Greek

$\alpha_{a j} \quad$ anodic transfer coefficient for the electrochemical reaction $j$

$\alpha_{c j} \quad$ cathodic transfer coefficient for the electrochemical reaction $j$

$\gamma \quad$ exponent on $\theta_{n}$ to account for nonlinearity of the specific surface area on state of charge of the cadmium electrode, $\gamma=1$ here

$\gamma_{i j} \quad$ exponentials of the exchange current density dependence of reaction $j$ on species $i$

$\begin{array}{ll}\varepsilon & \text { porosity of a porous electrode } \\ \varepsilon_{\max } & \text { porosity of a porous electrode at fully charged }\end{array}$ state

$\varepsilon_{0} \quad$ porosity of a porous electrode at fully discharged state

$\varepsilon_{\text {sub }} \quad$ porosity of a substrate plaque

$\eta_{\mathrm{j}} \quad$ overpotential of electrochemical reaction $j, \mathrm{~V}$ $\theta_{p} \quad$ state of charge of the positive electrode

$\theta_{n} \quad$ state of charge of the negative electrode

$\kappa \quad$ conductivity of the electrolyte $\mathrm{KOH}, \mathrm{S} / \mathrm{cm}$

$\lambda_{0,0} \quad$ absolute activity of the solvent at the reaction site

$\lambda_{0}^{0} \quad$ absolute activity of pure water

$\rho_{\mathrm{i}} \quad$ density of material, $i, \mathrm{~g} / \mathrm{cm}^{3}$

$\rho_{0}$ density of the solvent, g/liter

$\phi_{\mathrm{s}} \quad$ potential of solid phase, $\mathrm{V}$

$\phi_{1} \quad$ potential of liquid phase, $\mathrm{V}$

\section{REFERENCES}

1. D. Fan and R. E. White, This Journal, 138, 17 (1991).

2. R. Barnard, C. F. Randel, and F. L. Tye, J. Appl. Electrochem, 10, 109 (1980).

3. M. S. Spritzer, S-10344 NASA, Technical Report (1977).

4. Y. Li and H. Wu, Electrochim. Acta, 34, 157 (1989).

5. S. Atlung, K. West, and T. Jacobsen, This Journal, 126, $1311(1979)$

6. D. M. MacArthur, ibid., 117, 422 (1970).

7. P. C. Milner and U. B. Thomas, in "Advances in Electrochemistry and Electrochemical Engineering," Vol. 5, P. Delahey and C. W. Tobias, Editors, pp. 1-85, Interscience, New York (1967).

8. A. H. Zimmerman and P. K. Effa, This Journal, 131, 709 (1984).

9. J. Buoet and F. Richard, in "Nickel Hydroxide Electrodes," D. A. Corrigan and A. H. Zimmerman, Editors, PV 90-4, p. 260, The Electrochemical Society Softbound Proceedings Series, Pennington, NJ (1990).

10. P. D. Lukovtsev and G. J. Slaidin, Electrochim. Acta, 6, 17 (1962)

11. W. R. Scott and D. W. Rusta, "Sealed-Cell Nickel-Cadmium Battery Application Manual," NASA (1979).

12. D. R. Turner, W. E. Howden, Y. Okinaka, and E. J. McHenry, in "Power Sources," D. Collins, Editor, Pergamon Press, Inc., Elmwood, NY (1966).

13. E. G. Baars, in "Proceedings of 12th Annual Battery Research and Development Conference," p. 25, U.S. Army Signal Research and Development Laboratory, Fort Monmouth, NJ (1958).

14. H. B. Lunn and J. Parker, in "Proceedings of the 4th International Symposium on Research and Development in Non-Mechanical Electrical Power Sources," D. H. Collins, Editor, Pergamon Press, Inc., Elmwood, NY (1964).

15. K. Dehmelt and H. von Dohren, in "Proceedings of 13th Annual Power Sources Conference," U.S. Army Signal Research and Development Laboratory, Fort Monmouth, NJ (1959).

16. J. S. Newman, "Electrochemical Systems," PrenticeHall Inc., Englewood Cliffs, NJ (1973).

17. S. Chen, K. M. Yin, and R. E. White, This Journal, 135, 9 (1988).

18. Yu. M. Volfkovich and V. E. Soenskin, Elektrokhimiya, 14, 1570 (1978)

19. M. B. Armand, "Electrode Materials," D. W. Murphy, Editor, p. 145, Plenum Press, New York (1980).

20. D. Fan and R. E. White, This Journal, 138, 17 (1991).

21. B. E. Conway and T. C. Liu, in "Nickel Hydroxide Electrodes," D. A. Corrigan and A. H. Zimmerman, Editors, PV 90-4, p. 21, The Electrochemical Society Softbound Proceedings Series, Pennington, NJ (1990).

22. Z. Mao and R. E. White, Submitted to This Journal.

23. S. U. Falk and A. J. Salkind, "Alkaline Storage Batteries," Wiley, New York (1969).

24. P. Timmerman and S. DiStefano, Private communications.

25. K. W. Choi and N. P. Yao, in "Battery Design and Optimization," S. Gross, Editor, PV 79-1, p. 62, The Electrochemical Society Softbound Proceedings, Princeton, NJ (1979).

26. "CRC Handbook of Chemistry and Physics," 62nd ed. R. C. Weast, Editor, CRC Press, Cleveland, OH (1981).

27. Z. Tomczuk, K. E. Anderson, D. R. Vissers, and M. F. Roche, This Journal, 127, 1881 (1980).

28. R. E. White, S. E. Lorimer, and R. Darby, ibid., 130, 1123 (1983).

29. "Seated Nickel Cadmium Batteries," W. Raudszus, Editor, Varta Batterie AG (1982).

30. J. Van Zee, G. Kleine, R. E. White, and J. Newman, in "Electrochemical Cell Design," R. E. White, Editor, 
Plenum Press, NY (1984)

31. J. Newman, Ind. Eng. Chem. Fundam., 7, 514 (1968).

32. J. S. Newman, "Electrochemical Systems," Appendix C, Prentice-Hall Inc., Englewood Cliffs, NJ (1977).

33. R. E. White, Ind. Eng. Chem. Fundam., 367 (1978).

34. R. E. White, M. A. Nicholson, I. G. Kleine, J. Van Zee, and R. Darby, This Journal, 131, 268 (1984)

35. T. V. Nguyen, R. E. White, and H. Gu, ibid., 137, 2998 (1990).
36. T. Yeu, T. V. Nguyen, and R. E. White, ibid., 135, 1971 (1988).

37. D. Bernardi and J. Newman, ibid, 134, 1309 (1987).

38. K. Tsaur and R. Pollard, ibid., 131, 975 (1984).

39. R. E. White, Ph.D. Thesis, University of California at Berkeley (1975).

40. Z. Zlatev, Dept. of Computer Science, University of Aarhus, Aarhus, Denmark, 'Technical Report No. 111 (1980).

\title{
Corrosion Rate Measurement under Cathodic Polarization by Faradaic Rectification
}

\author{
Rengaswamy Srinivasan* and John C. Murphy \\ Applied Physics Laboratory, The Johns Hopkins University, Laurel, Maryland 20723-6099
}

\begin{abstract}
Cathodic polarization in corroding electrodes introduces the possibility of the electrode potential being close to the Nernst reversible potential $\left(E_{\mathrm{MT}}\right)$ of the metal dissolution/deposition reaction. While applying electrochemical techniques to measure corrosion rates for electrodes under cathodic polarization one needs to be cognizant of this and cannot make the usual assumption that the corrosion potential $\left(E_{\mathrm{cor}}\right)$ is far from $E_{\mathrm{Mr}}$. We propose here a technique based on faradaic rectification for instantaneous corrosion rate measurements of electrodes under cathodic polarization. Theory based on the first principles of electrode kinetics is explained. Corrosion rates of cathodically polarized steel in $0.5 \mathrm{M}$ sulfuric acid and $0.5 M$ sodium sulfate are computed using the derived theoretical expression.
\end{abstract}

Electrochemical techniques employed in corrosion rate measurements generally assume that the corrosion poten$\operatorname{tial}\left(E_{\text {cor }}\right)$ is far from the Nernst reversible potentials $E_{\mathrm{Mr}}(\mathrm{re}-$ action [1]) and $E_{\mathrm{Cr}}($ reaction [2])

$$
\begin{gathered}
\mathrm{M} \rightarrow \mathrm{M}^{n 1+}+n 1 e^{-} \\
\mathrm{O}+n 2 e^{-} \rightarrow \mathrm{R}
\end{gathered}
$$

These two reactions that form the conjugate couple are considered irreversible. The above assumptions are valid as long as $\left|E_{\text {cor }}-E_{\mathrm{Mr}}\right|$ and $\left|E_{\text {cor }}-E_{\mathrm{Cr}}\right|$ are both $>>R T / F$, where $R$ is the gas constant, $T$ is the temperature, and $F$ is the Faraday. However, under cathodic protection, where an electrode is polarized from $E_{\text {cor }}$ toward $E_{\mathrm{Mr}}$, it may not comply with the above assumptions. Furthermore, the reverse of reaction [1], namely

$$
\mathrm{M}^{n 1+}+n 1 e^{-} \rightarrow \mathrm{M}
$$

could also become possible. In practice cathodic protection is said to be achieved when the electrode is polarized to values close to cathodic to $E_{\mathrm{Mr}}$. The cathodic current, $i_{\mathrm{cp}}$, resulting from polarization of the electrode from $E_{\text {cor }}$ to a cathodic potential $E$ is given by

$$
\begin{aligned}
i_{\mathrm{cp}}=- & c_{\mathrm{dl}}(d E / d t)+i_{\mathrm{cor}}\left\{\exp \left[-\alpha_{\mathrm{c}} f\left(E-E_{\mathrm{cor}}\right)\right]\right\} \\
& +i_{\mathrm{o}, \mathrm{M}}\left\{\exp \left[-\delta_{\mathrm{c}} f\left(E-E_{\mathrm{Mr}}\right)\right]-\exp \left[\beta_{\mathrm{a}} f\left(E-E_{\mathrm{Mr}^{\mathrm{r}}}\right)\right]\right\}
\end{aligned}
$$

where $\alpha_{c}, \beta_{a}$, and $\delta_{c}$ are the overall Tafel constants for reactions [2], [1], and [3], respectively; the subscripts $c$ and a refer to the cathodic and anodic nature of the reactions; and $E$ is the potential to which the electrode is polarized. The variable $i_{o, M}$ in Eq. [4] represents the equilibrium exchange current density associated with reaction [1] and [3], $i_{\text {cor }}$ is the corrosion current density associated with the corroding electrode, and $f=F / R T$ where $F$ is the Faraday, $R$ is the gas constant, and $T$ is temperature. $C_{\mathrm{dl}}$ is the doublelayer capacitance. Equation [4] assumes that the electrode is under complete activation control and that masstransfer control is absent.

In Eq. [4] the second term on the right side corresponds to reaction [2] and the last two terms to reactions [1] and [3], respectively. Among the various parameters in this equation, only $i_{\mathrm{cp}}, E_{\mathrm{cor}}$, and $E$ are experimentally accessible, other than the Tafel constants. $i_{\mathrm{o}, \mathrm{M}}$ and $E_{\mathrm{M}^{\mathrm{r}}}$ are not experi-

* Electrochemical Society Active Member. mentally accessible, because corrosion systems generally allow the measurement of only $E_{\text {cor, }}$ which is a mixed potential of $E_{\mathrm{Mr}}$ and $E_{\mathrm{Cr}}$. Experimental techniques used in the determination of the corrosion current, $i_{\text {cor }}$, need to take this situation into consideration.

In contrast, when the electrode is not polarized from the corrosion potential and when $\left|E_{\text {cor }}-E_{\mathrm{Mr}}\right|$ and $\mid E_{\text {cor }}-$ $E_{\mathrm{Cr}} \mid$ are both $>R T / F$ the current due to the anodic reaction (Eq. [1]) and the cathodic reaction (Eq. [2]) balance each other. Thus

$$
\begin{aligned}
i_{\mathrm{cor}} & =i_{\mathrm{o}, \mathrm{C}}\left\{\exp \left[-\alpha_{\mathrm{c}} f\left(E_{\mathrm{cor}}-E_{\mathrm{Cr}}\right)\right]\right\} \\
& =i_{\mathrm{o}, \mathrm{M}}\left\{\exp \left[\beta_{\mathrm{a}} f\left(E_{\mathrm{cor}}-E_{\mathrm{Mr}}\right)\right]\right\}
\end{aligned}
$$

This is the basis for Eq. [6], which is the commonly used rate expression in corrosion rate measurements by various different electrochemical techniques

$$
\begin{aligned}
i=-C_{\mathrm{dI}}(d E / d t)+i_{\mathrm{cor}}\{\exp ( & \left.\left.-\alpha_{\mathrm{c}} f\left(E-E_{\text {cor }}\right)\right]\right\} \\
& -i_{\text {cor }}\left\{\exp \left[\beta_{a} f\left(E-E_{\text {cor }}\right)\right]\right\}
\end{aligned}
$$

Note that Eq. [6] does not contain any term corresponding to $E_{M^{r}}$ or $i_{\mathrm{o}, \mathrm{M}}$.

In this work, we propose a new theory based on faradaic rectification to measure corrosion rates of cathodically polarized electrodes. The faradaic rectification technique provides a way for solving $E_{\mathrm{Mr}}$ or $i_{\mathrm{o}, \mathrm{M}}$ in Eq. [4] and experimentally obtaining $i_{\text {cor }}$ at all levels of cathodic polarization. The theory is applied to experimental data obtained for ASTM A109 steel in $0.5 \mathrm{M} \mathrm{H}_{2} \mathrm{SO}_{4}$ and $0.5 M \mathrm{Na}_{2} \mathrm{SO}_{4}$ to derive corrosion rates as a function of cathodic polarization.

\section{Theory}

When an electrode/electrolyte interface is polarized by a dc potential, $E$, a net dc current, $i_{\mathrm{cp}}$, will result. If a smallamplitude ac sinusoidal excitation potential, $E_{\mathrm{p}} \cos (\omega t)$, is applied to the working electrode/electrolyte interface, the resulting current will have an ac component, $i_{\mathrm{ac}}$, to it. Furthermore, due to the property of rectification of the interface, a rectified dc current, $i_{\mathrm{fr}}$, will also flow through the interface. This process of rectification will also shift the dc potential of the electrode from $E$ to a new value $E_{1}$. Based on Eq. [4], the current-potential expression for the dc polarized system under ac perturbation is given by Eq. [7]. Equation [7] is valid for total activation control and no 